\title{
Analysis of Hazards for Hepatitis B Virus, Across Departments and Occupations, Among Health Care Workers in Public Hospitals in White Nile State, Sudan, 2013
}

\author{
Taha Ahmed Elmukashfi Elsheikh ${ }^{1, *}$, Abdelgadir Ali Bashir ${ }^{2}$, Siham Ahmed Balla ${ }^{1}$, \\ Asma Abdelaal Abdalla ${ }^{1}$, Mawahib Ahmed Elawad Abu Elgasim², Zeinab Swareldahab ${ }^{1}$ \\ ${ }^{1}$ Department of Community Medicine, Faculty of Medicine, University of Khartoum, Khartoum, Sudan \\ ${ }^{2}$ Khartoum State Ministry of Health, Khartoum, Sudan
}

Email address:

tahamukashfi@hotmail.com (T. A. E. Elsheikh), tahamukashfi@uofk.edu (T. A. E. Elsheikh)

${ }^{*}$ Corresponding author

To cite this article:

Taha Ahmed Elmukashfi Elsheikh, Abdelgadir Ali Bashir, Siham Ahmed Balla, AsmaAbdelaal Abdalla, Mawahib Ahmed Elawad Abu Elgasim, Zeinab Swareldahab. Analysis of Hazards for Hepatitis B Virus, Across Departments and Occupations, Among Health Care Workers in Public Hospitals in White Nile State, Sudan, 2013. American Journal of Health Research. Vol. 4, No. 5, 2016 , pp. 117-120. doi: 10.11648/j.ajhr.20160405.11

Received: July 3, 2016; Accepted: July 12, 2016; Published: August 10, 2016

\begin{abstract}
Background: Hepatitis B virus infection is a recognized occupational hazard for health care service providers. Aim: To determine hazard of HBV markers across department and occupation, among HCWs in public hospitals, White Nile State, Sudan. Methods: It was a cross sectional study, where 385 HCWs were selected randomly. Close ended questionnaire was used. From each respondent five ml venous blood was obtained, sera was separated and stored at-20 centigrade. Cross tabulation was performed together with Chi-square test. P value $\leq 0.05$ was considered statistically significant. Result: AntiHBcore: department of others (medicine, pediatrics, psychiatry, and ophthalmology) had got highest percentage (68.7\%), followed by obs. (17.4\%); the least was dentist (1.3\%). Regarding occupation nurse got highest percentage (31.7\%), followed by labor $(27.8 \%)$; the least was pharmacist $(2.6 \%)$. For HBsAg: department of others had got highest percentage of carrier rate (74.2\%); followed by obs. (17.7\%); the least was pharmacy (1.6\%). For occupation, labor got highest percentage (27.4\%), followed by nurse $(25.8 \%)$; the least was pharmacist, nurse and midwife not nurse $(1.6 \%)$. HBeAg: department of others had got highest percentage $(72.4 \%)$; followed by obs. $(20.7 \%)$; the least was surgery $(6.9 \%)$. For occupation labor got highest percentage $(34.5 \%)$, followed by doctor and Lab. technician $(24.1 \%)$; the least was nurse-midwife, and operation assistant $(3.5 \%)$. P value $=0.001$. Conclusion: Statistically there was association between HBV infection and type of department and occupation. The most hazardous department was other (medicine, pediatrics, psychiatry, and ophthalmology). HBsAg and $\mathrm{HBeAg}$ were high among laborers as occupation.
\end{abstract}

Keywords: Hazard of HBV Markers, HCWs, Public Hospitals, White Nile State, Sudan

\section{Introduction}

\subsection{Background Information}

The major cause of morbidity and mortality, globally, is Hepatitis $\mathrm{B}$ virus together with hepatitis $\mathrm{C}$ virus infection. $\mathrm{HBV}$ is endemic in Sub-Saharan Africa. HCWs are more vulnerable group for contracting HBV infection. In a study done in Indira Gandhi Medical College, Shimla, 5\% of HCWs show positivity of HBsAg; $40 \%$ of this is among the laboratory technicians [1, 2]. Chronic HBV infection is common among Tanzanian HCWs [2]. The overall HBV infection rate among Nigerian healthcare workers (HCWs) is $65.9 \%$; the highest portion of which is among the 
Gynecologists and Obstetricians (80\%) [3]. Infection and carrier rates among Iranian HCWs are $6.1 \%$ and $0.75 \%$ respectively and exposure to $\mathrm{HBV}$ and occupation is statistically associated among them [4]. In a study done among HCWs in Tanzania, $7.0 \%$ of them are chronically infected by $\mathrm{HBV}$ [5]. Reactive for $\mathrm{HBeAg}$ indicate high replication and accordingly high infectivity of the persons; they have 108 to $109 \mathrm{HBV}$ particles per ml of blood [6]. Globally; transmission of HBV from patients to HCWs is more than to patients from HCWs; where surgery, gynaecology, and orthopaedic are leading departments in this hazard [7]. The overall carrier rate of HBV among HCWs in Najran region, Saudi Arabia is 8.7\% [8]. Positive HbsAg among Northern Indian blood donors is $2.45 \%$ [9]. In a study done among HCWs in Public Hospitals, Khartoum State, Sudan; level of HBV markers is reported as: Anti-HBcore (57\%), HBsAg (6\%), and HBeAg (9\%) [10]. InUm Zukra village in Gezira State of Central Sudan; Anti-HBcore and HBsAg is $47.5 \%$ and $6.9 \%$ respectively [11]. Hazards of HBV infection among Health Care Workers in Public Teaching Hospitals in Khartoum State, Sudan, reported significant statistical association with department and occupation; leaded by department of surgery and occupation of nurses [12].

\subsection{Problem Statement and Justification}

Due to high endemecity of HBV in the Sudan and scarce resources allocated for health section; we planned, by the year 2013, to study the hazard of HBV infection across the different departments and occupations among HCWs in Public Hospitals, White Nile State, Sudan; in order to provide base line data to be utilized by the health planners.

\subsection{Objectives}

- To determine the level of HBV markers (Anti-HBcore, HBsAg, \&HBeAg) among HCWs in Public Hospitals, White Nile State, Sudan; 2013

- To measure the prevalence of HBV markers across departments and occupations in Public Hospitals, White Nile State, Sudan; 2013

\section{Materials and Methods}

\subsection{Study Design}

Cross sectional survey.

\subsection{Study Area}

Public Hospitals in White Nile State; Sudan; which are twenty three.

\subsection{Study Population}

They are 1808 heal care service providers working for more than 45 days in these hospitals.

\subsection{Sample}

Sample frame and sampling method:

It is composed of 1808 personnel working in 23 public hospitals in White Nile State. Using probability proportion to size; 13 hospitals were selected.

The sample size was calculated using the formula:

$\mathrm{n}=\mathrm{z}^{2} \mathrm{pq}(1)$

$\mathrm{d}^{2}$

$\mathrm{n}=$ sample size

$\mathrm{z}=$ confidence coefficient $=2$.

$\mathrm{p}=$ prevalence rate $=50 \%$.

$\mathrm{q}=(1-\mathrm{p})=50 \%$,

$\mathrm{d}$ (desired margin of error $)=0.05$.

So, $\mathrm{n}=2 \mathrm{X} 2 \times 0.5 \times 0.5=384.6=385$

$0.05 \times 0.05$

Proportional to the number of HCWs, sample size was divided across departments.

Selection of sample and data collection:

Randomly the respondents were selected. Informed consent was obtained. For the socio-demographic information we used close end questionnaire. Five mil of venous blood were taken; sera was separated and stored at$20^{\circ}$ centigrade. All respondents serum was tested for the presence of anti-HB core total; using ELISA. Reactive specimen was tested for HBsAg. Reactive specimen for HBsAg was tested for $\mathrm{HBeAg}$.

\subsection{Analysis}

SPSS was used. Frequency of the different HBV markers was obtained. Cross-tabulation and Chi-square test were done; $\mathrm{P}$ value $\leq 0.05$ was considered statistically significant.

\section{Results}

A total of three hundred and eighty five participants were surveyed. Two hundred and thirty one were female (60\%). Age composition was: $30.9 \%, 20.0 \%$ and $13.2 \%$ in the age group (27-36 years), (47-56) and 57+ respectively. Marital status was: $60 \%, 39 \%, 3 \%$, and $2 \%$ were married, single, widowed, and divorced respectively. About occupation $31.4 \%, 27.8 \%, 15.6 \%, 12.7 \%, 3.9 \%, 3.1 \%, 2.9 \%$, and $2.6 \%$ were labour, nurses, doctors, technicians in labs and blood banks, nurse midwives, pharmacists, theatre attendants and Village midwives respectively. These ro-prevalence of Anti-HBcore Total, HBsAg and HBeAg was 59.7\%, 27\%, and $46.6 \%$; respectively. 
Table 1. Distribution of Anti-HBc across departments and occupations of HCWs.

\begin{tabular}{|c|c|c|c|c|c|c|c|c|c|}
\hline \multirow{2}{*}{ Department } & \multicolumn{8}{|c|}{ HCWs occupation } & \multirow[b]{2}{*}{ - Total } \\
\hline & doctor & pharmacist & Nurse & Nurse-midwife & Midwife not nurse & Lab. Tech. & labour & Operation ass. & \\
\hline Surgery & $5(20.8 \%)$ & $0(0.0 \%)$ & $12(50.0 \%)$ & $1(4.2 \%)$ & $0(0.0 \%)$ & $0(0.0 \%)$ & $3(12.5 \%)$ & $3(12.5 \%)$ & $024(10.4 \%)$ \\
\hline Obs. & $16(40.0 \%)$ & $0(0.0 \%)$ & $7(17.5 \%)$ & $5(12.5 \%)$ & $7(17.5 \%)$ & $0(0.0 \%)$ & $5(12.5 \%)$ & $0(0.0 \%)$ & $040(17.4 \%)$ \\
\hline Dentist & $2(66.7 \%)$ & $0(0.0 \%)$ & $0(0.0 \%)$ & $0(0.0 \%)$ & $0(0.0 \%)$ & $0(0.0 \%)$ & $1(33.3 \%)$ & $0(0.0 \%)$ & $003(1.3 \%)$ \\
\hline Pharmacy & $0(0.0 \%)$ & $4(80.0 \%)$ & $1(20.0 \%)$ & $0(0.0 \%)$ & $0(0.0 \%)$ & $0(0.0 \%)$ & $0(0.0 \%)$ & $0(0.0 \%)$ & $005(2.2 \%)$ \\
\hline Other & $15(9.5 \%)$ & $2(1.3 \%)$ & $53(33.5 \%)$ & $2(1.3 \%)$ & $0(0.0 \%)$ & $27(17.1 \%)$ & $55(34.8 \%)$ & $4(2.5 \%)$ & $158(68.7 \%)$ \\
\hline Total & $38(16.5 \%)$ & $6(2.6 \%)$ & $73(31.7 \%)$ & $8(3.5 \%)$ & $7(3.1 \%)$ & $27(11.7 \%)$ & $64(27.8 \%)$ & $7(3.1 \%)$ & 230 \\
\hline
\end{tabular}

* Results are significant at $5 \%$ according to Chi-square test $(\mathrm{P}=0.001)$.

Looking at Table 1, department of others had got the highest percentage of infection rate (68.7\%), measured by Anti-Hcore; followed by obs. (17.4\%); the least one was the dentist (1.3\%). Regarding occupation nurse got the highest percentage (31.7\%), followed by labour (27.8\%); the least one was the pharmacist $(2.6 \%)$.

Table 2. Distribution of HBsAg across departments and occupations of HCWs.

\begin{tabular}{|c|c|c|c|c|c|c|c|c|c|}
\hline \multirow{2}{*}{ Department } & \multicolumn{8}{|c|}{ HCWs occupation } & \multirow{2}{*}{ Total } \\
\hline & doctor & pharmacist & nurse & Nurse-midwife & Midwife not nurse & Lab. Tech. & labour & Operation ass. & \\
\hline Surgery & $1(25.0 \%)$ & $0(0.0 \%)$ & $3(75.0 \%)$ & $0(0.0 \%)$ & $0(0.0 \%)$ & $0(0.0 \%)$ & $0(0.0 \%)$ & $0(0.0 \%)$ & $04(6.5 \%)$ \\
\hline $\begin{array}{l}\text { Obs. } \\
\text { Dentist }\end{array}$ & $8(72.7 \%)$ & $0(0.0 \%)$ & $0(0.0 \%)$ & $1(9.1 \%)$ & $1(9.1 \%)$ & $0(0.0 \%)$ & $1(9.1 \%)$ & $0(0.0 \%)$ & $11(17.7 \%)$ \\
\hline Pharmacy & $0(0.0 \%)$ & $1(100.0 \%)$ & $0(0.0 \%)$ & $0(0.0 \%)$ & $0(0.0 \%)$ & $0(0.0 \%)$ & $0(0.0 \%)$ & $0(0.0 \%)$ & $01(1.6 \%)$ \\
\hline Other & $4(8.7 \%)$ & $0(0.0 \%)$ & $13(28.3 \%)$ & $0(0.0 \%)$ & $0(0.0 \%)$ & $11(23.9 \%)$ & $16(34.8 \%)$ & $2(4.3 \%)$ & $46(74.2 \%)$ \\
\hline Total & $13(21.0 \%)$ & $1(1.6 \%)$ & $16(25.8 \%)$ & $1(1.6 \%)$ & $1(1.6 \%)$ & $11(17.8 \%)$ & $17(27.4 \%)$ & $2(3.2 \%)$ & $62(100 \%)$ \\
\hline
\end{tabular}

* Results are significant at $5 \%$ according to Chi-square test $(\mathrm{P}=0.001)$.

Table 2, indicated that department of others had got the highest percentage of carrier rate (74.2\%), measured by +veHBsAg; followed by obs. (17.7\%); the least one was pharmacy (1.6\%). For occupation laour got the highest percentage $(27.4 \%)$, followed by nurse (25.8\%); the least one was the pharmacist, nurse and midwife not nurse (1.6\%).

Table 3. Distribution of HBeAg across departments and occupations of HCWs.

\begin{tabular}{|c|c|c|c|c|c|c|c|c|c|}
\hline \multirow{2}{*}{ Department } & \multicolumn{8}{|c|}{ HCWs occupation } & \multirow{2}{*}{ Total } \\
\hline & Doctor & Pharmacist & nurse & Nurse-midwife & Midwife not nurse & Lab. Tech. & labour & Operation ass. & \\
\hline Surgery & $1(50.0 \%)$ & & $1(50.0 \%)$ & $0(0.0 \%)$ & & $0(0.0 \%)$ & $0(0.0 \%)$ & $0(0.0 \%)$ & $02(6.9 \%)$ \\
\hline Obs. & $5(83.3 \%)$ & & $0(0.0 \%)$ & $1(16.7 \%)$ & & $0(0.0 \%)$ & $0(0.0 \%)$ & $0(0.0 \%)$ & $06(20.7 \%)$ \\
\hline Dentist & & & & & & & & & \\
\hline Pharmacy & & & & & & & & & \\
\hline Other & $1(4.8 \%)$ & & $2(9.5 \%)$ & $0(0.0 \%)$ & & $7(33.3 \%)$ & $10(47.6 \%)$ & $1(4.8 \%)$ & $21(72.4 \%)$ \\
\hline Total & $7(24.1 \%)$ & & $3(10.3 \%)$ & $1(3.5 \%)$ & & $7(24.1 \%)$ & $10(34.5 \%)$ & $1(3.5 \%)$ & $29(100 \%)$ \\
\hline
\end{tabular}

* Results are significant at $5 \%$ according to Chi-square test $(\mathrm{P}=0.001)$.

Table 3, showed that department of others had got the highest percentage of high profile infectivity rate $(72.4 \%)$, measured by +veHBeAg; followed by obs. (20.7\%); the least one was surgery $(6.9 \%)$. For occupation labour got the highest percentage $(34.5 \%)$, followed by doctor and Lab. technician $(24.1 \%)$; the least one was the nurse-midwife, and operation assistant (3.5\%)

\section{Discussion}

Due to the high endemicity of HBV infection in this area [1], the department of others (medicine, pediatrics, ophthalmology and psychiatry) which are not at high level of exposure, had got the highest percentage of infection rate (68.7\%), measured by Anti-Hcore. This is similar to the finding to the overall $\mathrm{HBV}$ infection among Nigerian healthcare workers (HCWs) which is $65.9 \%$ [3]. It was deferred in that the highest infection rate is among the Gynecologists and Obstetricians (80\%) [3]. Here, in our study, obs. was the second one (17.4\%); the least was dentist (1.3\%). It is near to level of HBV infection among HCWs in Khartoum State; Sudan [10].

Regarding occupation, nurses got the highest percentage $(31.7 \%)$, followed by labour $(27.8 \%)$; the least one was the pharmacist $(2.6 \%)$. This is consistent with national study among HCWs in Khartoum State; Sudan; where nurses have got the highest level of HBV infection [12]. Regarding carrier rate (+veHBsAg) department of others (medicine, pediatrics, ophthalmology and psychiatry) had got the highest percentage of carrier rate $(74.2 \%)$; followed by obs. (17.7\%); the least one was pharmacy $(1.6 \%)$. This is a very high hazardous level for spreading of HBV infection. It is similar to what is reported in a case control study for the relation of HBV with hepatocellular carcinoma, in Khartoum, where 
$67 \%$ of patients have $+\mathrm{veHBsAg}$ [13]. For occupation laour got the highest percentage $(27.4 \%)$, followed by nurse $(25.8 \%)$; the least one was the pharmacist, nurse and midwife not nurse $(1.6 \%)$. This can be due to the fact that HBV infection is endemic in this region and that laborers have a higher exposure to waste products together with low compliance with infection control measures.

As far as a profile of high infectivity (+veHBeAg), department of others (medicine, pediatrics, ophthalmology and psychiatry) had got the highest percentage of high profile infectivity rate $(72.4 \%)$; followed by obs. $(20.7 \%)$; the least one was surgery $(6.9 \%)$. For occupation labour got the highest percentage (34.5\%), followed by doctor and Lab. technician $(24.1 \%)$; the least one was the nurse-midwife, and operation assistant $(3.5 \%)$. This is a very high and serious level of $+\mathrm{veHBeAg}$. We did not come across this level in research nationally or internationally. To our knowledge the possible explanation is that HBV infection is highly endemic in this region.

\section{Conclusion}

Statistically there was association between HBV infection and type of department and occupation. The most hazardous department was other (medicine, pediatrics, psychiatry, and ophthalmology). HBsAg and $\mathrm{HBeAg}$ were high among laborers as occupation.

\section{Referrences}

[1] Ganju SA1, Goel A. Prevalence of HBV and HCV infection among health care workers (HCWs). J Commun Dis. 2000 Sep; 32 (3): 228-30.

[2] Mueller et al. Prevalence of hepatitis B virus infection among health care workers in a tertiary hospital in Tanzania. BMC Infect Dis. 2015 Sep 23; 15: 386. doi: 10.1186/s12879-0151129-z.

[3] Ola SO, Odaibo GN, Olaleye OD, Ayoola EA. Hepatitis B and E viral infections among Nigerian healthcare workers; Afr J Med Med Sci. 2012 Dec; 41(4):387-91.
[4] Masomeh Bayani, Sepideh Siadati, Mahmoud Hajiahmadi, Afshin Khani, Navid Naemi. Hepatitis B Infection: Prevalence and Response to Vaccination among Health Care Workers in Babol, Northern Iran; Iranian Journal of Pathology (2014) 9 (3), 187-192.

[5] Mueller et al. Prevalence of hepatitis B virus infection among health care workers in a tertiary hospital in Tanzania. BMC Infectious Diseases (2015) 15:386.

[6] Beltrami et al. Risk and management of blood-borne infections inHCWs. Clinical microbiology reviews, July 2000, Vol. 13, No. 3; p. 385-407.

[7] Viral hepatitis Prevention Board (VHPB). Viral Hepatitis. November 2005Volume 14 - Number 1.

[8] Alqahtani et al. Seroprevalence of hepatitis B and C virus infections among health students and health care workers in the Najran region, southwestern Saudi Arabia: The need for national guidelines for health students. BMC Public Health 2014 9; 14: 577.

[9] Behal R, Jain R, Behal KK, Bhagoliwal A, Aggarwal N, Dhole TN. Seroprevalence and risk factors for hepatitis-B virus infection among general population in Northern India. Arq Gastroenterol; abr./jun. 2008; v. 45- no.2- page (137-140).

[10] Taha Ahmed Elmukashfi, Omer Ali Ibrahim, Isam Mohamed Elkhidir, Abdelgadir Ali Bashir \& Mohammed Ali Awad Elkarim. Socio-Demographic Characteristics of Health Care Workers and Hepatitis B Virus (HBV) Infection in Public Teaching Hospitals in Khartoum State, Sudan. Global Journal of Health Science; 2012; Vol. 4, No. 4; Page (37-41).

[11] Mudawi, et al. Prevalence of Hepatitis B Virus Infection in the Gezira State of Central Sudan. The Saudi Journal of Gastroenterology. Rabi' al-Awwal 1428 H April 2007; Volume 13, Number 2, Page (81-83).

[12] Taha Ahmed Elmukashfi, Omer Ali Ibrahim, Isam Mohamed Elkhidir, Abdelgadir Ali Bashir \& Mohammed Ali Awad Elkarim. Hazards Analysis, within Departments and Occupations, for Hepatitis B Virus among Health Care Workers in Public Teaching Hospitals in Khartoum State; Sudan. Global Journal of Health Science; 2012; Vol. 4, No. 6; Page (51-59).

[13] Itoshima $T$., et al. Hepatitis B virus markers in patients with schistosomiasis, liver cirrhosis and hepatocellular carcinoma in Khartoum, Sudan. Acta Med Okayama. 1989 Aug; 43 (4):241-4. 